\title{
DSP Based Implementation of Field Oriented Control for Induction Motor Drives
}

\author{
Bigyan Basnet \\ Department of Electrical Engineering \\ Tribhuvan Universtity, Kathmandu, Nepal
}

\begin{abstract}
This paper presents a practical implementation of field oriented control of three phase induction motor drives. In order to control the induction motor, TMS320F28335 digital signal processing(DSP) is used. Code composer studio is used to build the control algorithm in DSP. Induction motor drives control loop is divided into: inner current and outer speed control loop. An incremental encoder is attached at the motor shaft and a hall effect current sensor is used to detect the stator current of the motor. The performance of the drives system is simulated and experimentally verified under different speed commands.
\end{abstract}

Keywords - Digital Signal Processing, SVPWM, Induction Motor, Field Oriented Control

\section{INTRODUCTION}

Induction motor drive systems are widely used in industrial, commercial and domestic applications due to their simple structure, low cost, rugged and easy implementation. Control electronics, via microprocessors, DSP or FPGA's allow much less expensive and easier to employ software for system optimization instead of the complex hardware. The most important advantage of all these improvements is that the operating cost is reduced, by electronically reducing the speed instead of mechanical gears. One old traditional control method is V/Hertz control, which keep the flux of the motor constant by keeping the ratio of the voltage and frequency constant in order to provide a wide range of speeds. However, this method has a poor dynamic torque response and low speed accuracy especially in low rotor speed motor drives [1]. This old method has been phased out by more effective control methods such as Vector Control and Direct Torque Control [3]. In this chapter, we will discuss about Vector control method.

The distinguishing characteristic of field orientation control is to decouple the torque and flux. This method works in the similar way as separately-excited DC motor which operates with separated torque and flux, where the d component is assigned to control the flux while the q component is assigned to control the torque of motor. In field orientation control, there are two kinds of coordinate transformations: three phase to two phase (Clarke transformation), and stationary to rotation (Park transformation). Precise knowledge of the flux angle, $\theta_{\mathrm{e}}$ is to be acquired to accomplish the rotating transformation [2].

There are two basic ways to obtain the flux angle information: one is direct measurement, another is indirect estimation. Therefore, we end up having two types of field orientation control. It is not convenient to install a hall flux sensor inside the motor, and it is not practical for most industrial applications. Furthermore, it will decrease the reliability of the drive system. Therefore, this method is shadowed by the indirect field oriented control.

Indirect field orientation control(IFOC) proposed by $\mathrm{K}$. Hasse, estimates the rotor flux angle from some intermediate variables, such as the slip speed $\omega_{\mathrm{sl}}$ and rotor speed $\omega_{\mathrm{r}}$, instead of using the flux sensors [4]. TMS320F28335 is highly integrated, high-performance solutions for demanding control applications. having 32- bit external interface 16 channels ADC, 18 PWM outputs, 2 quadrature encoder interference is one of the best DSP chip for motor control.

Space vector pulse width Modulation (SVPWM) technique generates less harmonic distortion in the output voltage and currents and provides more efficient use of DC supply voltage compared to the sinusoidal modulation technique. Therefore, most of the induction motor speed drives prefers this scheme. 


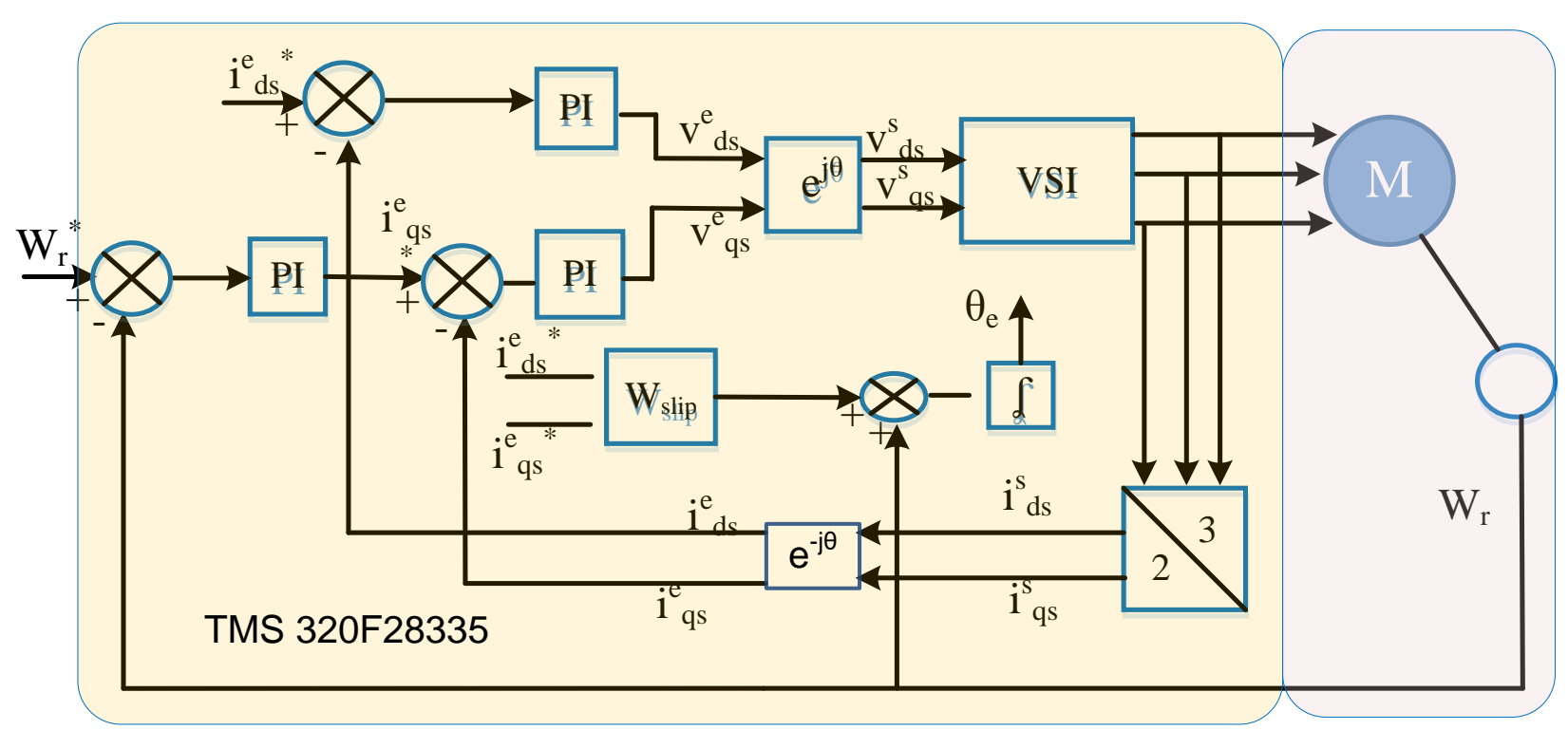

Figure 1. Block diagram of field oriented control.

This paper presents a practical implementation of field oriented control for induction motor drives using digital signal controller, TMS320F28335. The main aim of this paper is to investigate the performance of the induction motor drives in different speed condition. Transient and the steady states are examined for different rotor speed in both simulation and experimental results.

\section{FIELD ORIENTED CONTROL}

According to Stanley equations, for the machine model in stationary frame, when $\omega_{e}=0$, the stator circuit equations are written as:

$$
\begin{gathered}
v_{q s}^{s}=R_{s} i_{q s}^{s}+\frac{d}{d t} \psi_{q s}^{s} \\
v_{d s}^{s}=R_{s} i_{d s}^{s}+\frac{d}{d t} \psi_{d s}^{s} \\
0=R_{r} i_{q r}^{s}+\frac{d}{d t} \psi_{q r}^{s}-w_{r} \psi_{d r}^{s} \\
0=R_{r} i_{d r}^{s}+\frac{d}{d t} \psi_{d r}^{s}-w_{r} \psi_{q r}^{s} .
\end{gathered}
$$

Where, $R_{s}, R r=$ Stator and rotor resistances.

$\psi_{q s}^{s}, \psi_{d s}^{s}=$ q-axis and d-axis stator flux linkages.

$\psi_{q r}^{s}, \psi_{d r}^{s}=$ q-axis and d-axis rotor flux linkages.

The electromagnetic torque is developed by the interaction of air gap flux and rotor current which can be expressed in general vector form as:

$$
T_{e}=\frac{3}{2} \frac{p}{2}\left(\overline{\psi_{m}}\right) *\left(\overline{i_{r}}\right)
$$

The torque equations can be written in stationary frame with corresponding variables as: 


$$
T_{e}=\frac{3}{2} \frac{p}{2}\left(\psi_{d m}^{s} i_{q r}^{s}-\psi_{q m}^{s} i_{d r}^{s}\right)
$$

Other torque equations in stationary frame can be derived as follows:

$$
\begin{gathered}
T_{e}=\frac{3}{2} \frac{p}{2}\left(\psi_{d m}^{s} i_{q s}^{s}-\psi_{q m}^{s} i_{d s}^{s}\right) \\
T_{e}=\frac{3}{2} \frac{p}{2}\left(\psi_{d r}^{s} i_{q r}^{s}-\psi_{q r}^{s} i_{d r}^{s}\right) \\
\theta_{e}=\int w_{e} d t=\int\left(w_{s l}+w_{r}\right) d t \\
w_{s l}=\frac{L_{m} i_{s q}}{T_{r} \psi_{d r}}
\end{gathered}
$$

The rotor speed $\omega_{\mathrm{r}}$ is measured from a speed sensor attached on the motor shaft and it is more easy then attaching the flux sensor inside the motor.

The actual rotor speed measured from the rotor encoder is compared with the reference speed. The error generated is processed in the PI controller to generate the torque producing current called q component current. Then the generated d component from flux and q component from speed is compared with the respective park transformed current from the stator of induction motor is used to generate the voltage.

The Clarke and Park transformation is done for currents and voltage as shown in fig. 1 . The transformation can be done as

$$
\begin{aligned}
{\left[\begin{array}{l}
v_{a s} \\
v_{b s} \\
v_{c s}
\end{array}\right]=} & {\left[\begin{array}{ccc}
\cos \theta & \sin \theta & 1 \\
\cos \left(\theta-120^{\circ}\right) & \sin \left(\theta-120^{\circ}\right) & 1 \\
\cos \left(\theta+120^{\circ}\right) & \sin \left(\theta+120^{\circ}\right) & 1
\end{array}\right]\left[\begin{array}{c}
v_{q s}^{s} \\
v_{d s}^{s} \\
v_{o s}^{s}
\end{array}\right] } \\
& {\left[\begin{array}{c}
v_{d s}^{e} \\
v_{q s}^{e}
\end{array}\right]=\left[\begin{array}{cc}
\cos \theta & \sin \theta \\
-\sin \theta & \cos \theta
\end{array}\right]\left[\begin{array}{c}
v_{d s}^{s} \\
v_{q s}^{s}
\end{array}\right] }
\end{aligned}
$$

\section{SIMULATION RESULT}




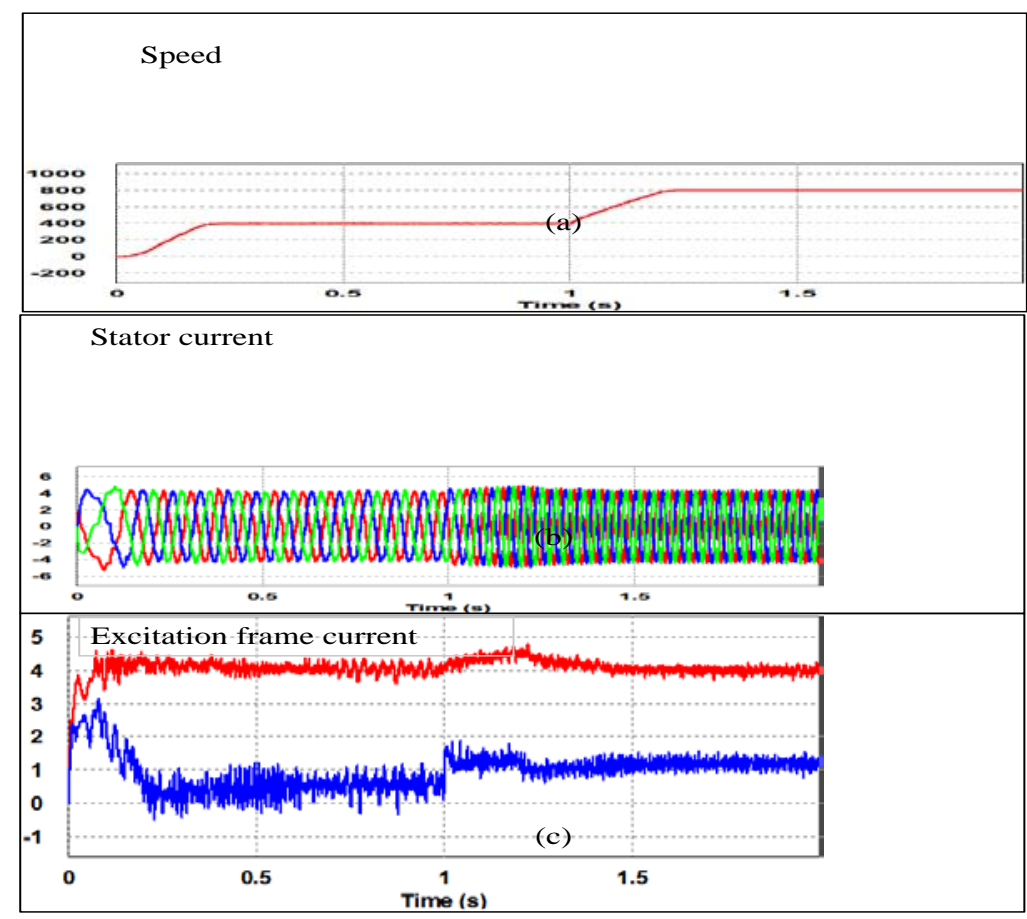

Figure 2. Simulated results with speed reference of 0-400-800 rpm. (a) rotor speed, (b) stator currents, (c) d-q currents.

Figure 2 shows the simulated results of the field oriented induction motor drives. The speed response is fast and accurate with the given reference speed of 400 and $800 \mathrm{rpm}$. The strating current is also limited with maximum 5A and is perfectly sinusodial. At $1 \mathrm{sec}$, when the speed reference is increased, slight increase in current is seen. However, this settles very quickly once the motor runs in steady state. Similarly, the torque controlling current (q) component is settled to 0 , once the rotor speed reaches steady state. While the d component which is used for flux control is limited to the reference value.

\section{EXPERIMENTAL RESULT}

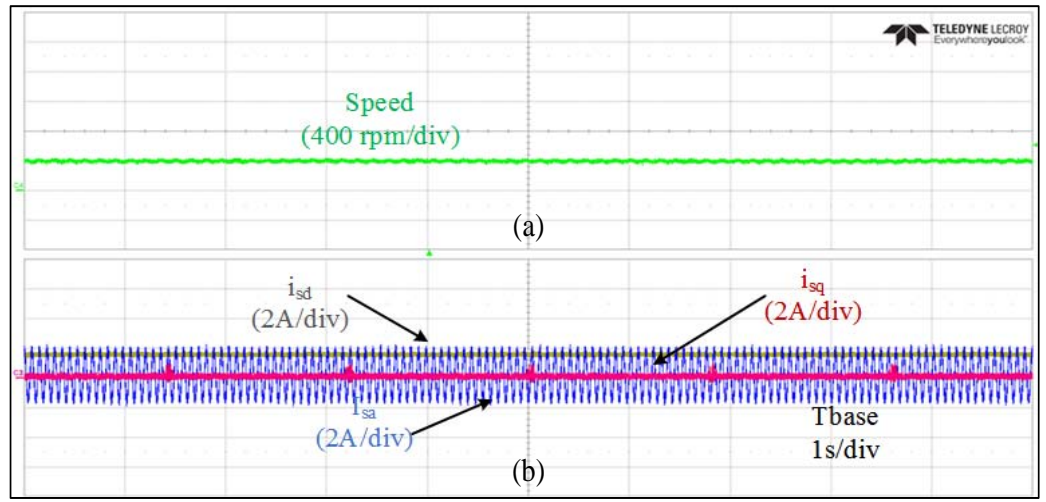

Figure 3. Experimental results of steady performance with speed reference of $400 \mathrm{rpm}$. (a) rotor speed, (b) stator and excitation frame currents.

Figure 3. shows the experimental results of the steady state, when the reference speed given is $400 \mathrm{rpm}$. Rotor speed is smooth and follows the reference speed. The current response in both stator and rotor frame is shown. The stator current is sinusoidal and the exciatation frame currents; $\mathrm{q}$ and $\mathrm{d}$ component are settled around 0 and given reference value, respectively. 


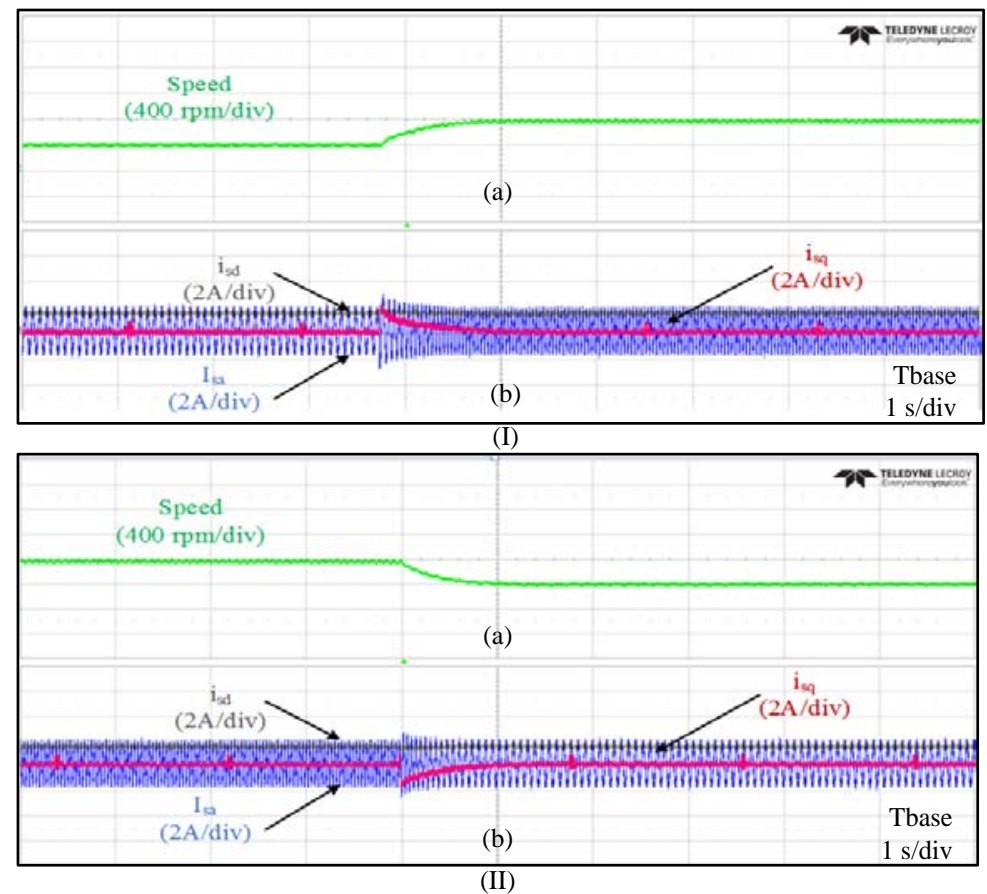

Figure 4. Experimental results of transient performance with speed reference of (I) $400-800 \mathrm{rpm}$ (II) $800-400 \mathrm{rpm}$. (a) rotor speed, (b) stator and excitation frame currents.

Figure 4. shows the experimental result for the transient performance of the induction motor drive. Figure 4.(I) shows the response from the low speed to high speed. Rotor speed achieves the steady state in a short time and is stable in both speed conditions. When the speed reference is raised the current also increases by a considerable amount but it settles in the same level once the steady response is achieved. Similarly, when the speed reference is dropped, significant amount of q component current is dropped. Infact the stator current is increased which settles in a short interval.

\section{IV.CONCLUSION}

The DSP implementation for field oriented control using space vector pulse width modulation technique of threephase induction motor was successfully developed. From the simulation and experimental result, the motor can operate in different speed command with very fast transient state. This experiment shows that highly complex algorithm can be simply controlled using the DSP with much accuracy.

\section{REFERENCES}

[1] Depenbrock, "Direct self control of inverter-fed induction machine," IEEE Trans.Power Electronics, vol.3. no.4, pp.420-429, Otc. 1988.

[2] Novotny, Donald and Lipo, Thomas, Vector control and dynamics of AC Drives,Oxford University Press, New York, 1996.

[3] B. Basnet, “Direct Torque Controlled Induction Motor Drive For Torque Ripple Reduction,” IJESRT, vol.6. pp.125-129, March,2017.

[4] K. Hasse, "Dynamic of adjustable speed drives with converter-fed squirrel cage induction motors" (Germany) Ph. D. Dissertation, Darmstadt, Technische. 